\title{
Spontaneous Activation of Latent
}

\section{Cytomegalovirus From Murine Spleen Explants}

\author{
ROLE OF LYMPHOCYTES AND MACROPHAGES \\ IN RELEASE AND REPLICATION OF VIRUS
}

\begin{abstract}
M. Colin Jordan and Vernon L. Mar, Infectious Diseases Laboratory, Veterans Administration Medical Center, Martinez, California 94553; Department of Internal Medicine, University of California School of Medicine, Davis, California 95616
\end{abstract}

\begin{abstract}
A B S T R A C T Cytomegalovirus (CMV) is a major pathogen in the compromised host where many infections result from activation of latent virus. Because latent CMV infection has been difficult to study in humans, murine models have been developed and investigated. Here, we describe the events involved in activation of latent murine CMV (MCMV) from spleen explants in vitro. Infectious virus was no longer detectable in murine organs 4 mo after inoculation of $10^{5}$ plaque-forming units of MCMV. 8-10 d after establishment of spleen explants, phagocytic macrophages covered $70-80 \%$ of the surface of tissue culture dishes, and lymphocytes were continuously released, reaching titers of $10^{6}$ cells $/ \mathrm{ml}$. MCMV was produced spontaneously after 12-18 d from spleen explant cultures of 33 of 34 mice. Virus replicated to titers above $10^{4}$ plaque-forming units $/ \mathrm{ml}$, remained at that level for 4-5 wk, and gradually disappeared as macrophages were lysed. Although MCMV was shown to be replicating in macrophages, these cells were never found to be the source of latent virus. Cell separation studies indicated that latent virus was initially released from $70 \%$ of lymphocyte cultures and was associated with the $B$ cell enriched fraction. We conclude that MCMV establishes nonreplicating dormant infection in B lymphocytes, activates from these cells in spleen explant cultures, and is augmented in titer by replication in permissive macrophages.
\end{abstract}

This work was presented in part at the Fifth International Congress of Virology, Strasbourg, France, August 4, 1981, and at the Western Society for Clinical Research, Carmel, CA, 18 February 1982.

Received for publication 17 May 1982 and in revised form 12 July 1982.

\section{INTRODUCTION}

The ability of herpesviruses to establish dormant or latent infections in the host is an important biological characteristic (1). In some instances, the tissue sites or even the specific cells that harbor latent virus have been identified experimentally. Thus, herpes simplex virus establishes latent infection in neurons of sensory ganglia (2-6), whereas the Epstein-Barr virus persists in a nonreplicating state in human B lymphocytes (7). In the case of cytomegalovirus $(\mathrm{CMV})^{1}$, however, the evidence that latent infection occurs is largely circumstantial, and the tissue or cellular sites maintaining latent virus in humans have not been identified conclusively (8-10). Infection is apparently transmitted from donor to recipient by blood transfusion or organ transplantation and may also be reactivated in pregnancy or in states of compromised immunity (10-15). Nevertheless, experimental attempts to recover latent virus from blood leukocytes or from transplanted donor renal allograft tissue have not been successful (16-19).

Definition and characterization of the latent viral state is fundamental to a basic understanding of the pathogenesis of CMV infection, especially since studies of live attenuated vaccine have now been initiated (2022). Because viral latency has been difficult to study experimentally in humans, murine models of latent CMV infection have been developed and characterized in recent years. In this report, we describe a model system in which previously undetectable murine CMV (MCMV) is activated spontaneously from spleen ex-

\footnotetext{
${ }^{1}$ Abbreviations used in this paper: CMV, cytomegalovirus; MCMV, murine CMV.
} 
plant cultures established in vitro. In these initial experiments, we have been able to characterize to an extent the viral and cellular events involved in latency and reactivation of MCMV.

\section{METHODS}

Mice. Female $\mathrm{C}_{3} \mathrm{H} / \mathrm{St}$ mice obtained from the Scripps Institute and Research Foundation, La Jolla, CA were used in all experiments. Animals were initially inoculated with virus at 4-6 wk of age.

Virus. Virulent MCMV was maintained by serial passage in mice. Virus stocks were prepared from $10 \%$ salivary gland homogenates of mice infected 2-3 wk earlier by intraperitoneal inoculation of $10^{5}$ plaque-forming units of MCMV. Homogenates were prepared in Eagle's minimal essential medium, and stored at $-70 \%$ after the addition of dimethyl sulfoxide at a $10 \%$ concentration. Quantitative assays of infectious virus were performed in secondary mouse embryo cells under overlay with $0.8 \%$ gum tragacanth or $0.2 \%$ agarose (23). Assay cultures were maintained at $37^{\circ} \mathrm{C}$ for $5 \mathrm{~d}$ and then stained with crystal violet for enumeration of plaques under a dissecting microscope. Viruses recovered from spleen explants were identified as MCMV by characteristic cytopathic effects and specific immunofluorescence of recovered virus grown in murine $3 \mathrm{~T} 3$ cells as previously described (24-26).

Establishment of latent MCMV infection. The techniques and criteria used in this laboratory to establish and define latent infection of mice with MCMV have been presented previously (27). Female $\mathrm{C}_{3} \mathrm{H} / \mathrm{St}$ mice, 4-6 wk old, were inoculated intraperitoneally with $1 \times 10^{5}$ plaque-forming units of virulent MCMV. 16 wk after inoculation, no infectious MCMV could be detected in the tissues of these animals except for $3-8 \%$ of mice with persistent low-level virus replication in the salivary glands (26). Animals with active viral infection were excluded from experiments after assay of surgically-resected salivary gland tissue for infectious MCMV in mouse embryo cell culture (23). Thus, animals classified as latently infected had no detectable virus in any organ. Techniques used in this laboratory that have failed to detect replicating virus in latently infected mice have been summarized elsewhere (26). More specifically, homogenates of spleen tissue or sonicated spleen cells suspensions did not yield infectious virus in cell culture.

Spleen explant cultures. To establish explant cultures, the spleen was removed aseptically from mice and minced with scissors into pieces $\sim 1 \times 1 \mathrm{~mm}$ in size. Four to six pieces of minced tissue were placed in each $35-\mathrm{mm}$-Diam well of plastic tissue culture plates (Co-star 3506, Data Packaging Corp., Cambridge, MÄ) containing $2.0 \mathrm{ml}$ of RPMI medium supplemented with $15 \%$ fetal calf serum and antibiotics. Six replicates of each spleen culture were usually established, and the plates were incubated at $37^{\circ} \mathrm{C}$ in an atmosphere of $5 \% \mathrm{CO}_{2}$ in air. The medium in each well was replaced every third day at which time the fluids removed were screened for the presence of infectious MCMV by assay in mouse embryo cells. The cellular characteristics and evolution of the spleen explant cultures is described in the Results section.

Separation of spleen cell populations. In experiments where suspensions of spleen cells were required, the spleen was bisected with scissors. The pulp of each spleen half was then gently extruded from the capsule using a tuberculin syringe containing $1 \mathrm{ml}$ of RPMI medium and fitted with a 26-gauge needle. The extruded spleen contents were gently dissociated by pipetting and the resulting cells were washed three times in fresh medium by centrifugation at $300 \mathrm{~g}$ for $10 \mathrm{~min}$. After adjustment to a concentration of $\sim 5 \times 10^{6}$ cells $/ \mathrm{ml}$ as determined in a hemocytometer, the cell suspensions were incubated in 6-12 16-mm-Diam wells of tissue culture plastic trays (Co-star 3524, Data Packaging). Before inoculation into the wells, cell viability was shown to be $\sim 95 \%$ by the trypan-blue dye exclusion method (27). Because the time required for spleen macrophages to adhere to glass or plastic surfaces is substantially greater than for peritoneal exudate cells (28), the cultures were left undisturbed for the first $72 \mathrm{~h}$. At that time, nonadherent lymphocytes were removed, resuspended in fresh medium, and either cultivated alone or cultivated along with virus-susceptible syngeneic mouse embryo cells, depending on the purposes of the experiment.

Cultures of spleen cell suspensions enriched for bone marrow-derived lymphocytes (B cells) or for thymus-derived lymphocytes ( $T$ cells) were required for certain experiments. Here, three different cell enrichment procedures were employed after removal of macrophages by surface adherence for $72 \mathrm{~h}$. Enriched B cell subpopulations were prepared by treatment of lymphocytes in suspension with a 1:10 dilution of rabbit anti-Thy 1.2 serum (anti- $\mathrm{C}_{3} \mathrm{H}$ Thy 1.2 , Litton Bionetics, Kensington, MD) for $60 \mathrm{~min}$ at $37^{\circ} \mathrm{C}$. Subsequently, $40 \mathrm{U}$ of $\mathrm{CH} 50$ guinea pig complement (Cordis Laboratories Inc., Miami, FL) were added before a second $60-\mathrm{min}$ incubation period (29). Less than $2 \%$ residual $\mathrm{T}$ cells remained after this procedure, as determined by sheep erythrocyte rosetting studies and by specific immunofluorescence staining with fluorescein isothiocyanate-conjugated monoclonal anti-Thy 1.2 antibody (anti-clone 30-HIZ, Becton, Dickinson, \& Co., Rutherford, NJ). T cell-enriched subpopulations were prepared by removal of B lymphocytes in nylon wool columns as described by Julius et al. (30) or in affinity columns containing $250-\mu \mathrm{m}$ beads coated with anti-mouse IgG antibody (31) (Bio-Rad Laboratories, Richmond, CA). By these two methods, the first eluant consisted of $90 \pm 3.3 \% \mathrm{~T}$ cells, as counted by fluorescence staining with rabbit fluorescein isothiocyanate conjugated anti-Thy 1.2 serum. The percentage of fluorescing cells collected was not altered by treatment with rabbit anti-mouse IgG serum (N. L. Cappell Laboratories Inc., Cochranville, PA) and complement. The second eluant from the columns consisted of $87 \pm 2.5 \% \mathrm{~B}$ cells as determined by immunofluorescence staining with the latter reagent. Treatment with anti-Thy 1.2 antiserum and complement had no effect on these counts.

Identification of macrophages. Macrophages were identified morphologically by staining with hematoxylin and eosin, and by characteristic ultrastructural features (32). To test phagocytic function, the monolayers of adherent cells were incubated with $0.02 \mathrm{ml}$ of a $10 \%$ suspension of $1.1 \mu \mathrm{m}$ polystyrene (latex) particles for $45 \mathrm{~min}$ at $37^{\circ} \mathrm{C}$. After three washes with phosphate-buffered saline to remove extracellular particles, the monolayers were examined microscopically and scored for ingestion of latex beads. In addition, macrophages were identified by staining for lysozyme content using specific rabbit antibody conjugated with horseradish peroxidase (33).

Electron microscopy. To prepare spleen explant cultures for ultrastructural examination, nonadherent cells were aspirated and then pelleted by low speed centrifugation in medium. Subsequently, macrophages were gently scraped from the surface of cell culture wells using a rubber-tipped glass rod and then also pelleted by centrifugation. Cell pellets were dehydrated, fixed in glutaraldehyde, embedded in Epon, and thin-sectioned for microscopy using standard ultrastructural procedures (34). 


\section{RESULTS}

Characterization of spleen explant cultures. After 4-6 d of incubation, adherent cells from the spleen explant cultures were noted to settle on the bottom surface of the tissue culture walls, eventually covering $70-80 \%$ of the surface area within $10 \mathrm{~d}$. (Fig. 1). At least $95 \%$ of these cells were shown to be macrophages by the methods described; $<2 \%$ were fibroblasts. In addition to the adherent cell population, lymphocytes were continually released into suspension from the spleen explant tissue, reaching concentrations of $\sim 10^{6}$ cells $/ \mathrm{ml}$ of culture fluid after $7 \mathrm{~d}$. Viability of lymphocytes (determined by trypan-blue dye exclusion) was $\sim 90 \%$ after $10 \mathrm{~d}$ in culture, $60 \%$ after $15 \mathrm{~d}$, and $24 \%$ after $28 \mathrm{~d}$.

Appearance of MCMV in the culture fluids. Between 12 and $18 \mathrm{~d}$ after explantation in vitro of spleen tissue from latently infected mice, MCMV appeared spontaneously in the culture fluids of explants established from the first $\mathbf{1 2}$ animals studied and from 33 out of 34 mice overall. In each experiment, activated

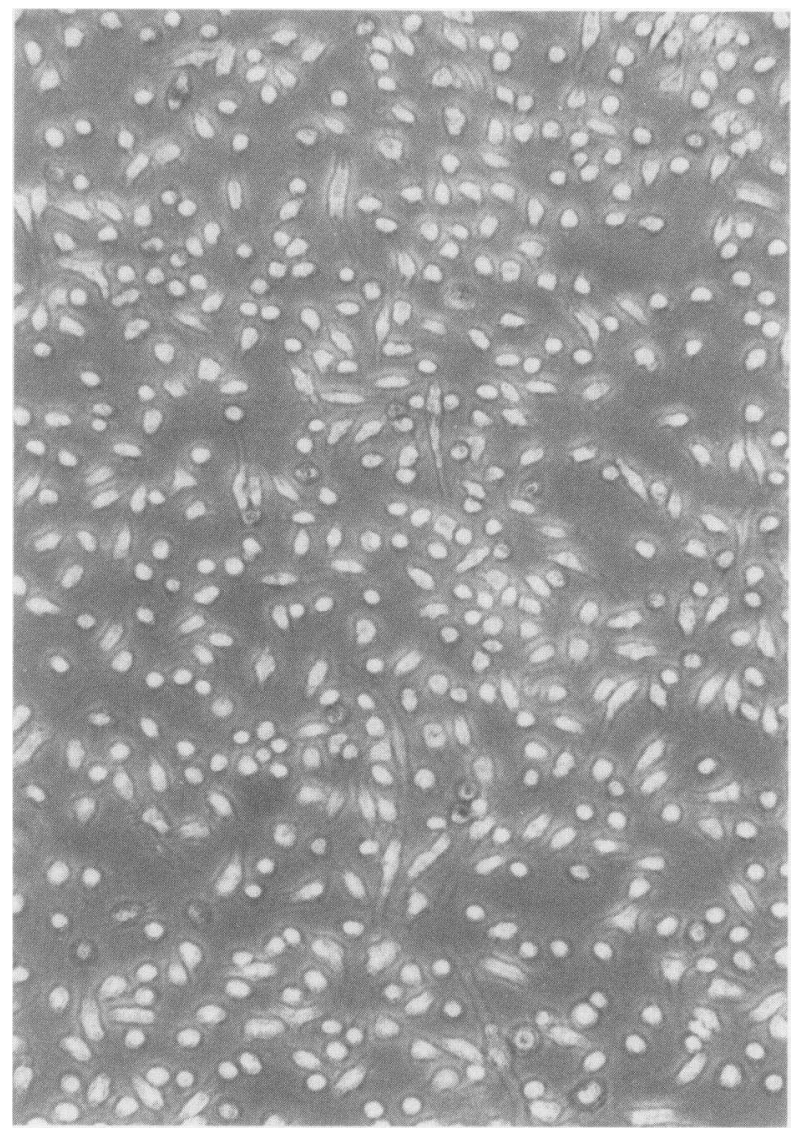

FiguRE 1 Phase-contrast photomicrograph $(\times 60)$ of adherent cells $10 \mathrm{~d}$ after explantation of spleen in vitro. 94-96\% of cells were phagocytic macrophages; $<2 \%$ were fibroblasts.

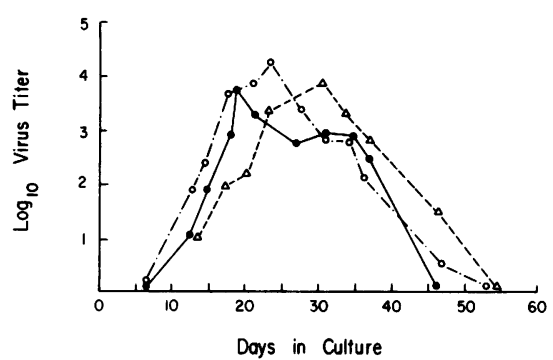

FIGURE 2 Spontaneous appearance and growth curve of MCMV after activation from three representative spleen explant cultures.

virus was detected in $80-100 \%$ of replicate wells cultured. Results of quantitative virus titrations of the fluids from three representative explant cultures are shown in Fig. 2. After initial detection, MCMV replicated to titers approaching $10^{5}$ plaque-forming units/ $\mathrm{ml}$ by the third week. The titer remained near this level for $\sim 5 \mathrm{wk}$, at which time it decreased gradually and virus could then be detected in the culture fluids only intermittently. Concurrently, a marked diminution in the number of adherent macrophages in the cultures was observed, suggesting that these cells had undergone lytic viral infection and were responsible for production of virus. In control spleen explant cultures (derived from uninfected animals), no decrease in the number of adherent macrophages was noted. By electron microscopy, MCMV nucleocapsids could be seen in the nuclei of macrophages $16 \mathrm{~d}$ after explantation of spleen tissue from latently infected mice (Fig. $3 \mathrm{~A}$ ). The majority of virions were defective, with only $20-25 \%$ containing central dense cores. Viral particles were eventually demonstrable in $\sim 10-15 \%$ of macrophages by ultrastructural analysis $24 \mathrm{~d}$ after the establishment of spleen explants. Virions were clearly associated with lytic infection of many of these cells (Fig. $3 \mathrm{~B}$ ). In no instance were viral nucleocapsids or defective particles detected in the nucleus or cytoplasm of lymhocytes examined by electron microscopy.

Although these observations indicated that macrophages were lytically infected with MCMV after viral activation, the source of latent virus had not yet been defined. Either lymphocytes or macrophages could have been responsible for release of MCMV after activation of virus. Therefore, the various cell populations in the spleen explant cultures were examined as possible sources of latent MCMV.

Identification of cells harboring latent MCMV. To determine whether splenic macrophages were the source of latent virus, these cells were allowed to adhere to the plastic surfaces of the culture vessels for $72 \mathrm{~h}$, after which the nonadherent cells were removed. One-half of the macrophage cultures were then over- 


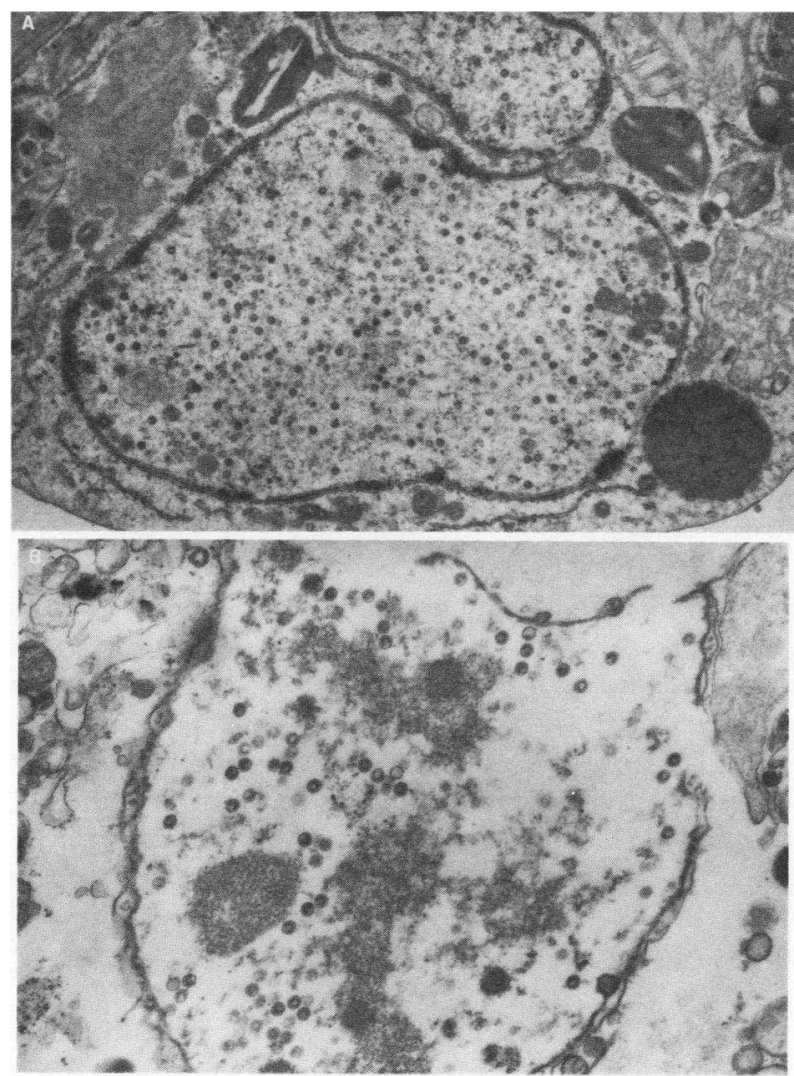

FIGURE 3 A. Electron photomicrograph $(\times 18,000)$ of macrophage containing MCMV virions in nucleus $16 \mathrm{~d}$ after spleen explant was established in vitro. B. Lytic MCMV infection of macrophage after $20 \mathrm{~d}$ in explant culture $(\times 31$,000). Virtually all MCMV particles lack electron-dense central cores.

laid with virus-susceptible mouse embryo cells and maintained for $30 \mathrm{~d}$. No viral cytopathic effects were noted in the 24 cultures established in this manner (Table I). The remaining macrophage cultures were maintained without mouse embryo cell overlay for 28 $d$, and the culture fluids were assayed for infectious virus every other day. Again, no MCMV was detected. These macrophages were then overlaid with mouse embryo cells. No MCMV was detected after observation for an additional $28 \mathrm{~d}$.

That latent MCMV did not activate in macrophage cultures suggested that these cells were not the source of latent virus. Nevertheless, the possibility remained that the presence of lymphocytes was in some way a requirement for activation of MCMV latent within macrophages. Therefore, crossover experiments were performed in which macrophages derived from spleens of six latently infected mice were co-cultured for 30 d with spleen lymphocytes from six uninfected mice, and vice versa. Under these conditions, activated MCMV could be recovered only when lymphocytes from latently infected animals were co-cultivated with macrophages from either latently infected or uninfected animals. However, MCMV was never detected in macrophage cultures established from latently infected mice maintained in the presence of lymphocytes from uninfected animals.

Taken together, these experiments suggested that, although macrophages underwent lytic viral infection in the spleen explant cultures and were responsible for production of infectious virus, they were not the cells harboring latent MCMV.

To determine whether spleen lymphocytes were latently infected, these cells were cultivated alone or along with virus-susceptible mouse embryo fibroblasts after removal of splenic macrophages by adherence. The lymphocyte cultures were maintained for $30 \mathrm{~d}$. As shown in Table I, MCMV activated from spleen lymphocyte cultures established from 6 out of 10 animals. When culture fluids were sampled every other day, no increase in titer of MCMV could be demonstrated. In 14 out of 19 mice, virus activated from spleen lymphocytes co-cultivated with mouse embryo cells (Table I). In each individual culture, MCMV was detected between 14 and $24 \mathrm{~d}$ of cultivation.

In the next experiments, subpopulations of splenic lymphocytes were established in culture after separation into components enriched for $B$ and $T$ cells. Macrophages were removed by adherence for $72 \mathrm{~h}$ before treatment of lymphocytes with anti-Thy 1.2 serum and complement, or separation of the cell populations with nylon wool, or by affinity chromatography. In each experiment, pooled spleen lymphocytes from four latently infected mice were distributed into 6-12 tissue culture wells at concentrations of $\sim 5 \times 10^{6}$ cells/well. As shown in Table II, latent

TABLE I

Spontaneous Activation of Latent MCMV from Spleen Tissue and Cells of Mice ${ }^{\circ}$

\begin{tabular}{cc}
\hline Source & $\begin{array}{c}\text { MCMV } \\
\text { activated }\end{array}$ \\
\hline Whole spleen explant & $33 / 34 \ddagger$ \\
Spleen macrophages & \\
Co-cultivation with MEC & $0 / 24$ \\
Cultivated alone & $0 / 22$ \\
Spleen lymphocytes & \\
Co-cultivation with MEC & $14 / 19$ \\
Cultivated alone & $6 / 10$ \\
\hline
\end{tabular}

- Spleen explants or spleen cells were derived from mice infected 4 mo earlier with MCMV and cultivated alone or with mouse embryo cells as indicated.

$\ddagger$ No. of mice from which MCMV activated/No. of mice tested. MEC, mouse embryo cells. 
TABLE II

Activation of Latent MCMV from Cell-enriched Spleen Suspension Cultures ${ }^{\circ}$

\begin{tabular}{lccc}
\hline \multicolumn{1}{c}{ Cell separation method } & $\begin{array}{c}\text { Total No. } \\
\text { mice used }\end{array}$ & B-enriched & T-enriched \\
\hline Anti-Thy 1.2 serum & & & \\
$\quad+$ complement & 6 & $13 / 44 \ddagger$ & - \\
Affinity bead column & 12 & $4 / 18$ & $0 / 18$ \\
Nylon wool & 12 & $3 / 24$ & $0 / 24$ \\
Total & 30 & $20 / 86$ & $0 / 42$ \\
\hline
\end{tabular}

- After removal of macrophages by adherence for $72 \mathrm{~h}$, spleen lymphocytes from three or four latently infected mice were pooled before separation into enriched cell populations by the three procedures noted. Subsequently, cell concentrations were adjusted to $5 \times 10^{6} / \mathrm{ml}$ and co-cultivated with mouse embryo cells in six to twelve replicate wells.

$\$$ No. wells from which MCMV activated/No. cultured.

MCMV could be activated by co-cultivation of the B cell-enriched population but was never detected in $\mathrm{T}$ cell-enriched suspensions. MCMV was first detected in the cultures after $20-30 \mathrm{~d}$ of co-cultivation. Viability of cells in cultures enriched for $T$ lymphocytes was greater than that noted in B cell-enriched cultures at the times of sampling (60\% vs. $20 \%$ at $10 \mathrm{~d}$, and $40 \%$ vs. $8 \%$ at $20 \mathrm{~d}$, respectively). Virus was found in only a small minority of the culture wells established in each experiment and activated with the lowest frequency after use of nylon wool or the affinity column for separation of cells. Assuming as a minimum that virus in each culture was liberated from a single lymphocyte, $\sim 1$ cell in $1.2 \times 10^{5}$ activated to produce infectious MCMV under these in vitro conditions.

\section{DISCUSSION}

To summarize these results, spleen explants were established from mice that had been infected 16-20 wk earlier with MCMV. Infectious virus was not present in homogenized spleen tissue or in sonicated spleen cell suspensions. After establishment of the explant culture, phagocytic macrophages eventually covered $70-80 \%$ of the surface area of the tissue culture wells. In addition, lymphocytes were continually released from the cultures, achieving concentrations of $\sim 10^{6}$ viable cells $/ \mathrm{ml}$ after $8-10 \mathrm{~d}$ of incubation. In cultures from virtually all mice, previously latent MCMV appeared in the culture fluids spontaneously, usually between 12 and $18 \mathrm{~d}$ of cultivation. Subsequently, MCMV replicated to titers approaching $10^{5}$ plaque-forming units $/ \mathrm{ml}$ of culture fluid and remained at that titer for $4 \mathrm{wk}$. Eventually, the amount of infectious virus declined coincidentally with the gradual disappearance from the cultures of nearly all adherent macrophages.
Ultrastructural studies indicated that $10-15 \%$ of macrophages were lytically infected with MCMV, whereas the amount of virus released as a result of productive infection of lymphocytes, if any, was extremely small and could not be quantified.

Although splenic macrophages were found to produce infectious virus once activation had occurred, these cells were never shown to be the initial source of latent MCMV when cultivated alone, in the presence of mouse embryo cells, or with lymphocytes derived from spleens of uninfected animals. However, virus was released from lymphocytes of latently infected mice in approximately two-thirds of the cultures. Activation of MCMV occurred equally well whether lymphocytes were cultured alone or cultured with susceptible syngeneic mouse embryo cells. Further experiments indicated that MCMV could be activated from the B cell-enriched lymphocyte fraction of spleen cells but not from $T$ cell-enriched cultures. Based on all of these points, we tentatively conclude, within the limits of the cell methods employed, that latent MCMV is harbored in a noninfectious form by splenic B lymphocytes. Virus activates spontaneously from these cells in culture, and subsequent amplification in titer of MCMV is due to secondary cytolytic infection of macrophages.

Latent MCMV has been activated by co-cultivation of splenic lymphocytes with virus-susceptible mouse embryo cells in three different laboratories (27, 3537). Olding and colleagues (35) also found that latent virus was associated with the B lymphocyte-enriched cell population. However, in their experiments, activation of MCMV occurred only when lymphocytes were cultivated with mouse embryo cells derived from allogeneic strains of mice. Allogeneic co-cultivation was clearly not required for activation of latent virus in our experiments because no fibroblasts were added in the explant cultures. Similarly, Mayo et al. did not find that allogeneic stimulation of spleen cell suspensions was a prerequisite for activation of virus in vitro or for transfer of MCMV infection to other mice by inoculation of latently infected lymphocytes $(36,37)$.

Our results confirm the preliminary studies of Wise et al. (38), who found spleen explantation more sensitive than cell suspension cultures for detection of latent MCMV. Thus, we could detect activation of latent virus from spleen explants of virtually all mice studied, and in most replicate explant cultures established. However, MCMV activation was detected in only twothirds of cell suspension cultures whether or not an indicator fibroblast monolayer was used. Manipulations employed for preparation of lymphocyte subpopulations ( $B$ and $T$ cells) reduced the yield still further in that activated MCMV could be found in only a small minority of replicate culture wells derived from pooled spleen cell suspensions of four animals. 
This diminution in frequency of activated MCMV suggests that virus is liberated from an extremely small percentage of lymphocytes in any given experiment and that manipulation in vitro damages cells, reducing their viability in long term culture.

Replication of MCMV has been studied by in vitro infection of macrophages in several laboratories. Most experiments have involved peritoneal exudate cells (39-42) and, to a lesser extent, pulmonary macrophages (43). In general, these cells have been permissive for viral infection, although virus yields are substantially lower than those found in mouse embryo cell culture. In addition, the kinetics of virus production are prolonged and characterized by delayed spread of infection to adjacent cells $(39,43)$. As found in our experiments, a majority of virions in infected macrophages are defective, lacking electron-dense central cores (43). Although MCMV infection of splenic macrophages has not been studied extensively, viral replication after spontaneous activation of latent virus is similar to the growth curve observed when peritoneal or pulmonary macrophages are infected experimentally in vitro.

On the other hand, experiments designed to establish whether MCMV replicates productively in lymphocytes are difficult to interpret. Hudson et al. (44) showed that infection of spleen cells in vitro resulted in production of infectious centers in only 0.01-1.0\% of the total cell population. Whether the cells forming infectious centers were in fact lymphocytes could not be ascertained. Wu and Ho (45) studied MCMV infection of $B$ and $T$ lymphocytes in vivo during acute infection established by intravenous inoculation of virus. Virus was detected in only a small fraction of blood lymphocytes (1-6 cells in 104). We could not detect replication of MCMV in lymphocytes using quantitative assays of viral infectivity or repeated ultrastructural examinations after reactivation of latent virus. However, conditions were not optimal for virus replication because the viability of lymphocytes had been reduced by cultivation in vitro.

Latent MCMV infection does not appear to be restricted to the spleen. Cheung and Lang (46-48) have presented evidence that dormant virus may persist in salivary glands, prostate, and peripheral blood. We have described another model in which latent MCMV can be consistently activated and disseminated by immunosuppression, yet virus cannot be detected by cocultivation of spleen tissue or other organs (25-27). The site of viral latency has not yet been defined in these animals. Other sites that have been implicated in maintenance of latent MCMV infection are peritoneal macrophages (42) and spermatogenic cells (49).

Despite strong clinical and epidemiologic evidence that CMV causes latent infections in humans, a direct experimental demonstration of the phenomenon has been most difficult. The cells or tissues that have been strongly implicated include peripheral blood leukocytes $(11,18)$, kidney $(13,14)$, colon $(50)$, and heart (51). In the murine model, definition of the sites of viral latency and elucidation of host and viral factors involved in maintenance and reactivation of latent virus will continue to provide valuable insight relevant to human investigation.

\section{ACKNOWLEDGMENTS}

We thank Dr. Gloria Yu and Mr. Lynn leFevre for their assistance and suggestions regarding the electron microscopy.

This work was supported by Veterans Administration Research Funds and by a gift from the Mary Hodge Fleming Trust, Houston, TX.

\section{REFERENCES}

1. Stevens, J. G. 1977. Latent characteristics of selected Herpesviruses. Adv. Cancer Res. 26: 227-254.

2. Stevens, J. G., and M. C. Cook. 1971. Latent herpes simplex virus in spinal ganglia of mice. Science (Wash. DC). 173: 843-845.

3. Bastian, F. D., A. S. Rabson, C. L. Yee, and T. S. Tralka. 1972. Herpesvirus hominis. Isolation from human trigeminal ganglion. Science (Wash. DC). 178: 306-307.

4. Baringer, J. R., and P. Swoveland. 1973. Recovery of herpes simplex virus from human trigeminal ganglia. $N$. Engl. J. Med. 288: 648-654.

5. Baringer, J. R. 1974. Recovery of herpes simplex virus from human sacral ganglions. N. Engl. J. Med. 291: 828833.

6. Cook, M. L., V. B. Bastone, and J. G. Stevens. 1974. Evidence that neurons harbor latent herpes simplex virus. Infect. Immun. 9: 946-951.

7. Adams, A., and T. Lindahl. 1975. Epstein-Barr virus genomes with properties of circular DNA molecules in carrier cells. Proc. Natl. Acad. Sci. U. S. A. 72: 14771481.

8. Weller, T. H. 1971. The cytomegaloviruses. Ubiquitous agents with protean clinical manifestations. N. Engl. J. Med. 285: 203-214, 267-274.

9. Ho, M. 1981. The lymphocyte in infections with EpsteinBarr virus and cytomegalovirus. J. Infect. Dis. 143: 857862.

10. Jordan, M. C. 1982. Latent infection and the elusive cytomegalovirus. Rev. Infect. Dis. In press.

11. Yeager, A. S., F. L. Grumet, E. B. Hafleigh, A. M. Arvin, J. S. Bradley, and C. J. Prober. 1981. Prevention of transfusion-acquired cytomegalovirus infection in newborn infants. J. Pediatr. 98: 281-287.

12. Numazaki, Y., N. Yanos, T. Morizuka, S. Takai, and N. Ishida. 1970. Primary infection with human cytomegalovirus. Virus isolation from healthy infants and pregnant women. Am. J. Epidemiol. 91: 410-417.

13. Ho, M., S. Suwansirikul, J. N. Dowling, L. A. Youngblood, and J. A. Strong. 1975. The transplanted kidney as a source of cytomegalovirus infection. N. Engl. J. Med. 293: 1109-1112.

14. Betts, R. F., R. B. Freeman, and R. G. Douglas. 1975. Transmission of cytomegalovirus infection with renal allograft. Kidney Int. 8: 387-393.

15. Lang, D. J. 1972. Cytomegalovirus infections in organ transplantation and post-transfusion. Arch. Gesamte Virusforsch. 37: 365-372. 
16. Mirkovic, R., J. Werch, M. A. South, and M. BenyeshMelnick. 1971. Incidence of cytomegaloviremia in blood bank donors and in infants with congenital cytomegalic inclusion disease. Infect. Immun. 3: 45-60.

17. Kane, R. C., W. E. Rousseau, G. R. Noble, G. E. Tegtmeier, H. Wulff, H. B. Herndon, T. D. Y. Chin, and W. C. Bayer. 1975. Cytomegalovirus infection in a volunteer blood donor population. Infect. Immun. 11: 719723.

18. Bayer, W. L., and G. E. Tegtmeier. 1976. The blood donor. Detection and magnitude of cytomegalovirus carrier states and the prevalance of cytomegalovirus antibody. Yale J. Biol. Med. 49: 5-12.

19. Naraqi, S., G. G. Jackson, O. Jonasson, and M. Rubenis. 1978. Search for latent cytomegalovirus in renal allografts. Infect. Immun. 19: 699-703.

20. Plotkin, S. A., J. Farquar, and E. Homberger. 1976. Clinical trials of immunization with the Towne 125 strain of human cytomegalovirus. J. Infect. Dis. 134: 470-475.

21. Neff, B. J., R. E. Weibel, E. B. Buynak, A. R. McLean, and M. R. Hilleman. 1979. Clinical and laboratory studies of live cytomegalovirus vaccine Ad-169. Proc. Soc. Exp. Biol. Med. 160: 32-37.

22. Glazer, J. P., H. M. Friedman, R. A. Grossman, S. E. Starr, C. F. Barker, L. J. Perloff, E. S. Huang, and S. A. Plotkin. 1979. Live cytomegalovirus vaccination of renal transplant candidates: a preliminary trial. Ann. Intern. Med. 91: 676-683.

23. Jordan, M. C., J. D. Shanley, and J. G. Stevens. 1977. Immunosuppression reactivates and disseminates latent murine cytomegalovirus. J. Gen. Virol. 37: 419-425.

24. Jordan, M. C. 1978. Interstitial pneumonia and subclinical infection after intranasal inoculation of murine cytomegalovirus. Infect. Immun. 21: 275-280.

25. Shanley, J. D., M. C. Jordan, M. L. Cook, and J. G. Stevens. 1979. Pathogenesis of reactivated latent murine cytomegalovirus infection. Am. J. Pathol. 95: 67-80.

26. Jordan, M. C. 1980. Adverse effects of cytomegalovirus vaccination in mice. J. Clin. Invest. 65: 798-803.

27. Jordan, M. C., J. L. Takagi, and J. G. Stevens. 1982. Activation of latent murine cytomegalovirus in vivo and in vitro. A pathogenetic role for acute infection. J. Infect. Dis. 145: 699-705.

28. Bennett B. 1966. Isolation and cultivation in vitro of macrophages from various sources in the mouse. Am. J. Pathol. 48: 165-178.

29. Starr, S. E., and A. C. Allison. 1977. Role of T-lymphocytes in recovery from murine cytomegalovirus infection. Infect. Immun. 17: 458-462.

30. Julius, M. D., E. Simpson, and L. A. Herzenberg. 1973. A rapid method for the isolation of functional thymusderived murine lymphocytes. Eur. J. Immunol. 3: 645649.

31. Mage, M. G., L. L. McHugh, and T. L. Rothstein. 1977. Mouse lymphocytes with and without surface immunoglobulin. Preparative scale separation on polystyrene tissue culture dishes coated with specifically purified immunoglobulin. J. Immunol. Meth. 15: 47-56.

32. Carr, I. 1981. Morphological identification of macrophages. In Manual of Macrophage Methodology. H. B. Herscowitz, editor. Marcel Dekker, Inc., New York. 187-198.

33. Gordon, S., J. Todd, and Z. A. Cohn. 1974. In vitro synthesis and secretion of lysozyme by mononuclear phagocytes. J. Exp. Med. 139: 1228-1248.
34. Morgan, C., H. M. Rose, and B. Medearis. 1968. Electron microscopy of herpes simplex virus. I. Entry. J. Virol. 2: 507-513.

35. Olding, L. B., F. C. Jensen, and M. B. A. Oldstone. 1975. Pathogenesis of cytomegalovirus infection. I. Activation of virus from bone marrow-derived lymphocytes by in vitro allogenic reaction. J. Exp. Med. 141: 561-572.

36. Mayo, D. R., J. A. Armstrong, and M. Ho. 1977. Reactivation of murine cytomegalovirus by cyclophosphamide. Nature (Lond.). 267: 721-723.

37. Mayo, D., J. A. Armstrong, and M. Ho. 1978. Activation of latent murine cytomegalovirus infection: co-cultivation, cell transfer, and the effect of immunosuppression. J. Infect. Dis. 138: 890-898.

38. Wise, T. G., J. E. Manischewitz, G. V. Quinnan, G. S. Aulakh, and F. A. Ennis. 1979. Latent cytomegalovirus infection of Balb/c mouse spleens detected by an explant culture technique. J. Gen. Virol. 44: 551-556.

39. Tegtmeyer, P. J., and J. E. Craighead. 1968. Infection of adult mouse macrophages in vitro with cytomegalovirus. Proc. Soc. Exp. Biol. Med. 129: 690-694.

40. Selgrade, M. F., and J. E. Osborne. 1974. Role of macrophages in resistance to murine cytomegalovirus infection. Infect. Immun. 10: 1383-1390.

41. Mims, C. A., and J. Gould. 1978. The role of macrophages in mice infected with murine cytomegalovirus. J. Gen. Virol. 41: 143-153.

42. Brautigam, A. R., F. J. Dutko, L. B. Olding, and M. B. A. Oldstone. 1979. Pathogenesis of murine cytomegalovirus infection: the macrophage as a permissive cell for cytomegalovirus infection, replication, and latency. J. Gen. Virol. 44: 349-359.

43. Shanley, J. D., and E. L. Pesanti. 1980. Replication of murine cytomegalovirus in lung macrophages: effect on phagocytosis of bacteria. Infect. Immun. 29: 1152-1159.

44. Hudson, J. B., L. Loh, V. Misra, B. Judd, and J. Suzuki. 1977. Multiple interactions between murine cytomegalovirus and lymphoid cells in vitro. J. Gen. Virol. 38: 149-159.

45. Wu, B. C., and M. Ho. 1979. Characteristics of infection of $B$ and $T$ lymphocytes from mice after inoculation with cytomegalovirus. Infect. Immun. 24: 856-864.

46. Cheung, K. S., and D. J. Lang. 1977. Detection of latent cytomegalovirus in murine salivary and prostate explant cultures and cells. Infect. Immun. 15: 568-575.

47. Cheung, K. S., and D. J. Lang. 1977. Transmission and activation of cytomegalovirus with blood transfusion. $J$. Infect. Dis. 135: 841-845.

48. Cheung, K. S., E. S. Huang, and D. J. Lang. 1980. Murine cytomegalovirus: detection of latent infection by nucleic acid hybridization technique. Infect. Immun. 27: 851854.

49. Dutko, F. J., and M. B. A. Oldstone. 1979. Murine cytomegalovirus infects spermatogenic cells. Proc. Natl. Acad. Sci. U. S. A. 76: 2988-2991.

50. Roche, J. K., K. S. Cheung, I. Boldogh, E. S. Huang, and D. J. Lang. 1981. Cytomegalovirus detection in human colonic and circulating mononuclear cells in association with gastrointestinal disease. Int. J. Cancer. 27: 657659.

51. Preiksaitis, J. K., C. Grumet, and T. C. Merigan. 1982. Cytomegalovirus infection in cardiac transplant recipients: The role of the donor heart. Clin. Res. 30: 99 (Abstr.). 